DOI: 10.4172/2254-609X.10009

\section{Supratentorial Intraparenchymal Hemorrhage after Spinal Meningioma Surgery}

Received: May 01, 2015; Accepted: July 07, 2015; Published: July 10, 2015

A 52-year old woman was admitted with radiating left leg pain and weakness while walking for approximately six months. Neurological examination revealed left lower monoparesis (3/5) and T8 hypoesthesia with bilateral Babinski sign. Thoracic vertebral magnetic resonance image (MRI) demonstrated a mass lesion causing a nearly total occlusion of the spinal canal (Figure 1). We removed the tumor totally in prone position via T5 and 6 laminectomy. The neuropathological examination showed it to be meningotheliamatous meningioma. Cerebrospinal fluid (CSF) leakage during the operation continued postoperatively through the subfascial drain though the dura was closed properly. At the second day of the operation, the patient began to complain about headache. Though we didn't observe additional neurological deficit, CT scan demonstrated a right parietooccipital intracerebral hemorrhage (Figure 2). The patient was treated conservatively. We stopped subfascial drainage and her complaints regressed without any additional neurological defisit [1] (Figure 3).

Supratentorial intracerebral hemorrhage in post spinal intradural surgery patients are extremely rare. The mechanism of intracranial hemorrhage is commonly explained by intracranial hypotension and traction of cerebral veins due to CSF loss. A similar mechanism also explains the headache due to lumbar puncture (LP) and spinal anesthesia. Apart from the patients developing neurological deficits, most cases benefit from conservative therapy. Avoiding CSF loss, plasma volume expansion and applying epidural patch for persistant headache are treatment choices. The patients headache in our case improved in a few days after the removal of subfascial drain [2-4].

In order to determine the real frequency of intracerebral hemorrhage due to CSF loss resulting from spinal surgery, spinal anesthesia, and LP we recommend brain imaging studies to be done in cases with headache even without neurological deficits as in our case.
Kirişoğlu M Ü ${ }^{1}$, Ösüin $A^{2}$, Atay $B^{1}$ and Samancıoğlu $A^{1}$

\section{Buca Seyfi Demirsoy State Hospital, Department of Neurosurgery İzmir, Turkey \\ 2 Dumlupınar University Medical School, Department of Neurosurgery, Kütahya, Turkey}

\section{Corresponding author: Kirişoğlu Mehmet Ünal}

MD, Buca Seyfi Demirsoy State Hospital, Department of Neurosurgery İzmir, Özmen Cad. No:145, Buca/Izmir, Turkey.

झ mukirisoglu@yahoo.com

Citation: Kirişoğlu MÜ, Ösün A, Atay B, et al. Supratentorial Intraparenchymal Hemorrhage after Spinal Meningioma Surgery. J Biomedical Sci. 2016, 4:2.

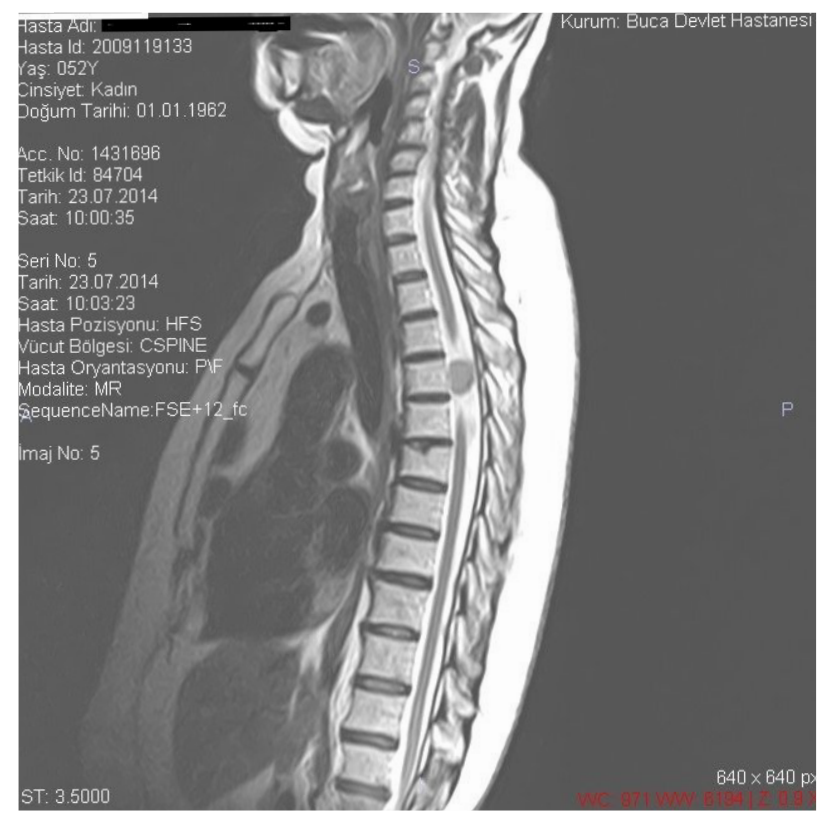

Figure 1 Thoracic vertebral magnetic resonance image (MRI). 


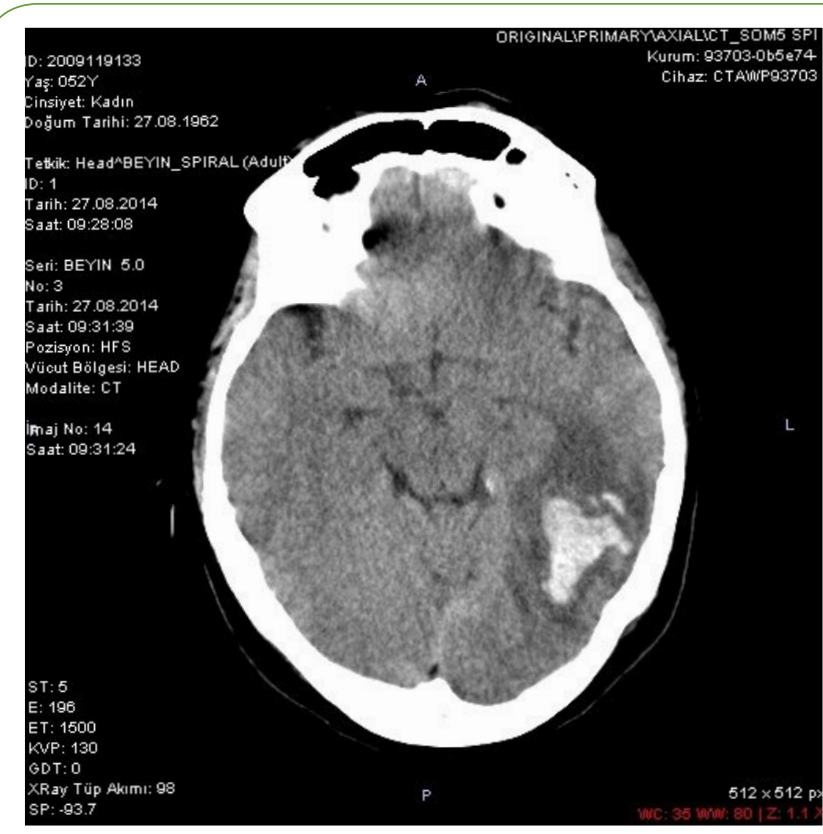

Figure 2 CT scan demonstrated a right parietooccipital intracerebral hemorrhage.

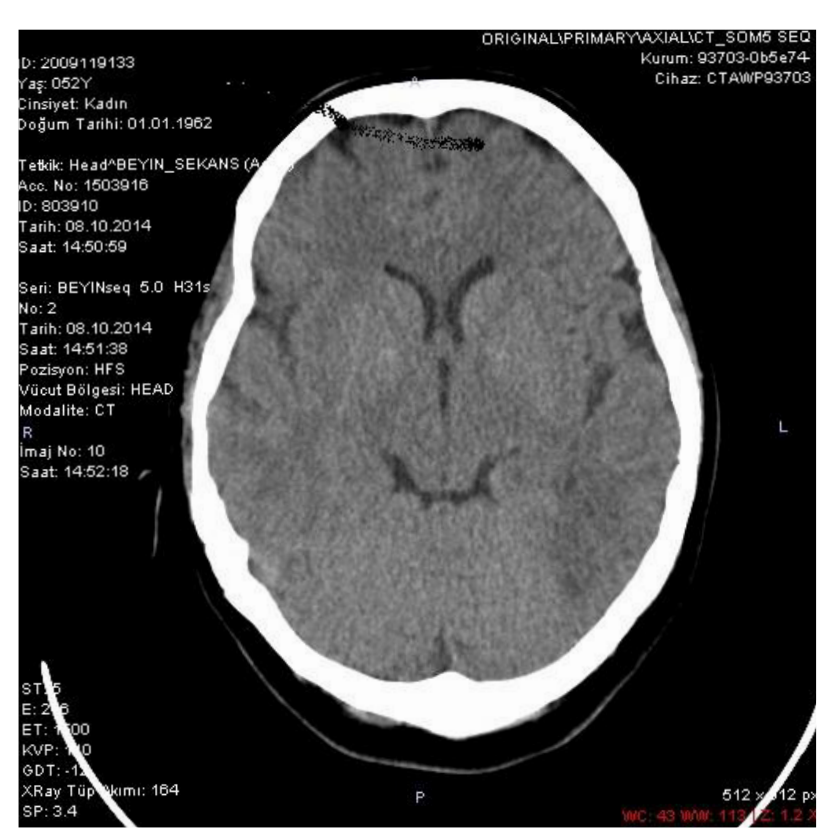

Figure 3 Supratentorial intracerebral hemorrhage. 


\section{References}

1 Gilberto Ka Kit Leung, Johnny Ping Hon Chan (2014) Supratentorial intraparenchimal haemorrhages during spine surgery: case report. J Korean Neurosurg soc 55: 103-105.

2 Çakır CÖ, Baloğlu M, Ataizi ZS (2014) Supratentorial hemorrhage following spinal tumor surgery: Konuralp Tıp Dergisi 6: 53-56.
3 Moradi M, Shami S, Farhadifar F, Nesseri K (2012) Cerebral subdural hematoma following spinal anesthesia: Report of two cases: Hindawi journals 2012: 4.

4 Greenberg MS (2010) Headache in:Greenberg MS (ed), Handbook of Neurosurgery, Thieme, 2010: 57-59 